ARTIGO

\title{
DO PROJETO PEDAGÓGICO À AULA UNIVERSITÁRIA: APRENDER A ENSINAR COM TDIC EM CURSOS DE LICENCIATURA EM MATEMÁTICA
}

\author{
ROSEMARA PERPETUA LOPES ${ }^{1}$ \\ ORCID: https://orcid.org/0000-0002-5498-2025 \\ MONICA FÜRKOTTER ${ }^{2}$ \\ ORCID: https://orcid.org/0000-0003-3479-5289
}

\begin{abstract}
RESUMO: Partindo de resultados que apontaram a formação para o uso das Tecnologias Digitais de Informação e Comunicação (TDIC) nos projetos pedagógicos de dois cursos de Licenciatura em Matemática de uma universidade pública do estado de São Paulo, realizamos uma pesquisa com o objetivo geral de investigar essa formação a partir de dados coletados com alunos concluintes, por questionário, e com professores e coordenadoras, por entrevista semiestruturada. Constatamos que, na prática, em cada curso essa formação é promovida por uma disciplina: uma com enfoque em mídias e outra com enfoque na produção de material didático. Porém, aos olhos dos participantes, a formação para o uso das TDIC existiu em outras disciplinas e em toda atividade, inclusive extraclasse, que envolveu tecnologia, ocorrendo em situações que vão do "aprender sobre" ao "aprender a ensinar com" tecnologia; tais situações, isoladamente, não comportam o conhecimento tecnológico e pedagógico do conteúdo (TPACK), além de não estarem asseguradas ao futuro professor, quando inscritas em optativas ou circunscritas à metodologia de um professor. Subjacentes às atividades descritas estão a concepção realista, comum a todos os participantes, a otimista, verificada somente entre os alunos, e a pessimista - todas elas carregando conflitos epistemológicos, evidenciados, por exemplo, nos casos em que a concepção (construcionista) de aprendizagem do professor não converge com os meios (instrucionistas) adotados por ele para propiciá-la ao aluno. Concluímos que, se efetiva, a formação anunciada nos projetos poderia fazer a diferença na constituição do professor como agente da mudança, apto ao exercício da profissão em contextos inusitados.
\end{abstract}

Palavras-chave: tecnologias digitais, formação de professores, licenciatura em Matemática.

\section{FROM THE PEDAGOGICAL PROJECT TO THE UNIVERSITY CLASSROOM: LEARNING TO TEACH WITH DTIC IN DEGREE COURSES IN MATHEMATICS}

\begin{abstract}
Based on results that pointed out the training for the use of Digital Technologies of Information and Communication (DICT) in pedagogical projects of two undergraduate teaching degrees in Mathematics at a public university in the state of São Paulo, we conducted a research to investigate this training by collecting data with graduating students, through a questionnaire, and with teachers and coordinators, through semi-structured interview. We found that, in practice, each course

\footnotetext{
${ }^{1}$ Universidade Federal de Goiás, Faculdade de Educação (UFG). Goiânia, GO, Brasil. >rosemaralopes@ufg.br>.

${ }^{2}$ Universidade do Oeste Paulista, Programa de pós-graduação em Educação. (UNOESTE). Presidente Prudente, SP, Brasil.

<monicaf@unoeste.br>.
} 
promotes this training through a discipline, one focusing media, and the other the production of teaching material. However, participants believe that the training to use DICT has taken place in other disciplines, in all activities involving technology, even extraclass, in situations ranging from "learning about" to "learning to teach with" technology. When considered separately, those situations do not support technological and pedagogical content knowledge (TPACK), as well as not being assured to the future teacher, when enrolled as an optional subject or circumscribed to a teacher's methodology. Underlying the activities described are the realistic conception, common to all participants; the optimistic one, seen only among students; and the pessimistic one. All conception carry epistemological conflicts, evidenced, for example, in cases when teachers' (constructionist) conception learning do not converge with the (instrumentalist) means adopted by them to interact with the students. We conclude that, if effective, the training announced in the projects could make a difference in the constitution of the teacher as an agent of change, able to work in unusual contexts.

Keywords: digital technologies, teacher training, undergraduate teaching degree in Mathematics.

\section{DEL PROYECTO PEDAGÓGICO A LA CLASE UNIVERSITARIA: APRENDER A ENSEÑAR CON TDIC EN CURSOS DE LICENCIATURA EN MATEMÁTICAS}

RESUMEN: Basado en resultados que señalaron la capacitación para el uso de las Tecnologías de Información y Comunicación Digital (TDIC) en proyectos pedagógicos de dos cursos de Licenciatura en Matematicas en una universidad pública en el estado de São Paulo, realizamos una investigación sobre esta formación con datos de alumnos concluyentes, a través de un cuestionario, y con maestros y coordinadores, a través de entrevistas semiestructuradas. Descubrimos que, en la práctica, cada curso promueve esta capacitación en una disciplina: una enfocada en los medios y otra enfocada en la producción de material didáctico. Sin embargo, los participantes creen que la capacitación para el uso de TDIC ha existido en otras disciplinas, en cada actividad que involucraba tecnología, incluida la clase extra, que ocurría en situaciones que iban desde "aprender sobre" hasta "aprender a enseñar con" tecnología, que , de forma aislada, no incluyen el conocimiento tecnológico y pedagógico del contenido (TPACK), además de no estar garantizado para el futuro maestro, cuando se inscribe de manera opcional o circunscrita a la metodología de un maestro. Subyacente a las actividades descritas se encuentra la concepción realista, común a todos los participantes, y la optimista, verificada solo entre los estudiantes, además de la pesimista, que llevan conflictos epistemológicos, evidenciados, por ejemplo, en casos donde la concepción (construccionista) del aprendizaje del maestro no converge con los medios (instruccionistas) adoptados por él. Concluimos que, si efectiva, la capacitación anunciada podría marcar la diferencia en la constitución del maestro como agente de cambio, capaz de ejercer la profesión en contextos inusuales.

Palabras clave: tecnologías digitales, formación del profesorado, licenciatura en Matemáticas. 


\section{INTRODUÇÃO}

Apresentamos os resultados de uma pesquisa de doutorado que teve como ponto de partida os dados obtidos em outra, de mestrado, realizada por meio de análise documental, com o objetivo geral de investigar se a formação do professor que atuará na Educação Básica inclui conhecimentos sobre Tecnologias Digitais de Informação e Comunicação (TDIC) e sob qual paradigma pedagógico eles se articulam. Os resultados da pesquisa de mestrado apontaram a formação para o uso das TDIC nos projetos pedagógicos de dois cursos de Licenciatura em Matemática de uma universidade pública do estado de São Paulo — os únicos, de um contingente de 123 cursos de formação de professores de três universidades públicas do referido estado, a incluírem em seus projetos a referida formação ${ }^{3}$.

Isso posto, a pesquisa da qual tratamos neste artigo teve como objetivo geral investigar a formação para o uso das TDIC em dois cursos de Licenciatura em Matemática de uma universidade pública do estado de São Paulo. Os objetivos específicos consistiram em: analisar como ocorre a articulação ${ }^{4}$ entre disciplinas obrigatórias e optativas presentes nos projetos pedagógicos dos cursos, destinada a formar para o uso das TDIC; identificar as concepções dos estudantes sobre ensino e aprendizagem com TDIC; evidenciar as concepções dos professores formadores e dos coordenadores de curso sobre como ensinar com TDIC; investigar situações que, do ponto de vista dos participantes, propiciaram a formação para o uso das tecnologias.

Tendo em vista esses objetivos, buscamos responder à seguinte questão: como ocorre a formação para o uso das TDIC contemplada nos projetos pedagógicos de dois cursos de Licenciatura em Matemática de uma universidade pública do estado de São Paulo, segundo as concepções inferidas dos dados fornecidos por aqueles que a protagonizam e as práticas por eles declaradas?

Conforme indicam os objetivos específicos e a questão de pesquisa, buscamos apreender as concepções dos participantes sobre ensino e aprendizagem, analisando-as quanto ao posicionamento diante das tecnologias na educação e à abordagem teórica subjacente à prática pedagógica. Ao focalizálas, pressupomos que elas carregam indícios da formação dos alunos concluintes, bem como dos princípios epistemológicos que fundamentam a prática pedagógica do professor formador. Por sua vez, as concepções das coordenadoras possibilitam compreender melhor os dados apurados junto aos alunos e professores.

Sobre a "formação para o uso das TDIC", esta expressão pressupõe que todo ato pedagógico é também político (FREIRE, 2014), de maneira que os fins determinam os meios do trabalho educativo. Em sua composição, a palavra "formação" indica aquela que ocorre em curso de licenciatura, enquanto "uso das TDIC" significa não um uso qualquer, seja qual for o contexto, mas, sim, integrado ao processo de ensino e aprendizagem escolar. A "tecnologia", por sua vez, é compreendida como ferramenta criada pelo homem para facilitar a sua vida em sociedade (KENSKI, 2014), a ser incorporada à educação formal como ferramenta mediadora (COLL; MAURI; ONRUBIA, 2010). Ao priorizar as TDIC, nós as vislumbramos como um conjunto de tecnologias que se distingue das Tecnologias de Informação e Comunicação (TIC) pela presença do digital. Neste artigo, além da sigla TDIC, empregamos, também, os termos "tecnologia digital" e "tecnologia" para designá-las.

Assim, desenvolvemos uma pesquisa de cunho qualitativo, coletando os dados por meio de questionário, composto por perguntas fechadas e abertas, aplicado a alunos concluintes de dois cursos de Licenciatura em Matemática de uma universidade pública do estado de São Paulo, identificados como Curso de Matemática 1 (CM1) e Curso de Matemática 2 (CM2). Ao todo, participaram 25 alunos, identificados como Aluno 1 (A1), Aluno 2 (A2) e assim sucessivamente, distribuídos em três turmas: duas do CM1, diurno e noturno, Turma 1 (T1) e Turma 2 (T2), respectivamente, compostas por 15 alunos ao todo; e uma do CM2, Turma 3 (T3), com dez alunos. Ao longo da análise, a identificação

\footnotetext{
${ }^{3}$ No decorrer deste texto, ao fazermos referência aos projetos pedagógicos dos cursos participantes da pesquisa, retomamos a análise documental e os resultados obtidos nesse nosso estudo anterior.

${ }^{4}$ Sobre a articulação mencionada no primeiro objetivo específico, assim denominada nos projetos pedagógicos, ela corresponde ao meio adotado pelos cursos para promover ao egresso a formação investigada. 
inclui Aluno 1 da Turma 1 (A1T1), Aluno 1 da Turma 2 (A1T2), Aluno 1 da Turma 3 (A1T3), Aluno 2 da Turma 1 (A2T1) etc.

Além do questionário, realizamos uma entrevista semiestruturada com 14 professores, identificados como Professor 2 (P2) ${ }^{5}$, Professor 3 (P3) e assim por diante, selecionando os que ministraram as disciplinas indicadas nos projetos pedagógicos como responsáveis por promover a formação pesquisada e os que ministraram as disciplinas apontadas pelos alunos no questionário como envolvidos nessa formação. Das 26 disciplinas mencionadas por eles, priorizamos para a entrevista as informadas com maior frequência. Desse modo, no CM1, entrevistamos os professores de Didática (P6 e P14), Noções de Ensino de Matemática Usando o Computador (P7), Introdução à Computação (P12 e P13) e Metodologia do Ensino de Matemática I e II (P4, P5 e P11). No CM2, Análise Crítica de Livros Didáticos (P3), Ensino de Matemática por Múltiplas Mídias (P2 e P3), Estrutura e Funcionamento do Ensino Fundamental e Médio (P9), Introdução à Programação de Computadores (P8 e P10) e Práticas de Ensino de Matemática I e II (P2 e P3).

Em ambos os cursos, nos casos em que uma mesma disciplina foi ministrada por dois ou três professores, a exemplo de Metodologia do Ensino de Matemática I e II, todos os professores (P4, P5 e P11) foram entrevistados. Por sua vez, o professor que ministrou mais de uma das disciplinas indicadas, por exemplo, Análise Crítica de Livros Didáticos, Ensino de Matemática por Múltiplas Mídias e Prática de Ensino de Matemática I e II, foi abordado em uma única ocasião (caso de P3). A entrevista abrangeu, também, a Coordenadora 1 (C1), a Coordenadora 2 (C2) e a Coordenadora 3 (C3), esta última do CM1, e as duas primeiras do $\mathrm{CM}_{2}^{6}$.

Os dados coletados foram analisados com o respaldo de Bardin (2016), em quatro unidades, cada qual composta por categorias e indicadores próprios. A primeira privilegiou a articulação prevista nos projetos pedagógicos dos cursos, anteriormente referida; a segunda e a terceira trataram das concepções dos participantes sobre ensino e aprendizagem com TDIC; e a quarta primou por situações de aprendizagem com tecnologias presentes na formação dos futuros professores. Desse modo, a formação foi investigada a partir do olhar daqueles que a protagonizaram ${ }^{7}$.

A relevância do estudo está em rediscutir a formação inicial do professor, compreendida por Gatti, Barretto e André (2011) como a base da profissionalização docente. Durante o curso de licenciatura, a formação compõe-se não somente dos conteúdos previstos no currículo formal, mas de conhecimentos tácitos (SCHÖN, 1997), oriundos da experiência, no caso, das vivências em sala de aula. Nesse ambiente, do ponto de vista da simetria invertida (PIRES, 2002), o aluno aprende do mesmo modo que se pretende que ele venha a ensinar. Nessa perspectiva, adquire destaque a prática do professor formador, que leciona em curso superior de licenciatura (BATISTA, 2018), na medida em que essa prática sinaliza para o lugar da tecnologia na aula, reforçando ou ressignificando concepções anteriormente construídas pelo futuro professor da Educação Básica.

O posicionamento do professor com relação às tecnologias é influenciado por suas concepções sobre ensino e aprendizagem. De acordo com Rosado (1997), não se muda a prática pedagógica sem afetar concepções, pressuposto que se coaduna aos de Fagundes (2008) e, também, de Marcelo Garcia (1997), para quem o pensar orienta o fazer docente. Segundo Garnica (2008), não sendo diretamente observáveis, as concepções podem ser apreendidas de modo indireto em situações práticas. Ressalvadas as limitações da licenciatura, no que diz respeito à ação sobre as concepções dos estudantes (MARCELO GARCIA, 1997; GARNICA, 2008), compreendemos que nesse período o futuro professor não deve ser privado do acesso ao conhecimento tecnológico e pedagógico do conteúdo (TPACK).

O modelo de TPACK desenvolvido por Koehler \& Mishra (2005) utilizou como origem a concepção da Base de Conhecimento, de Shulman (1986, 1987), especificamente do

\footnotetext{
${ }^{5}$ O Professor 1 (P1) participou somente da aplicação-piloto da entrevista, por isso iniciamos por P2.

${ }^{6} \mathrm{C} 1$ sucedeu a C2 durante o percurso formativo dos alunos concluintes do CM2, participantes da pesquisa abordada.

${ }^{7}$ As transcrições apresentadas neste artigo, extraídas do questionário respondido ou da entrevista, são fidedignas ao original, portanto, sem correções.
} 
Conhecimento Pedagógico de Conteúdo, concepção na qual foi explicitamente integrado o componente de Conhecimento Tecnológico (CIBOTTO; OLIVEIRA, 2017, p. 13).

O TPACK ${ }^{8}$ emerge do entrelaçamento entre o conhecimento do conteúdo de ensino, o conhecimento "relacionado aos processos e às práticas de ensino" (CIBOTTO; OLIVEIRA, 2017, p. 14) e aquele que se refere à "tecnologia digital e de outras anteriores" (CIBOTTO; OLIVEIRA, 2017, p. 15). Combinados, esses conhecimentos mostram que a ação de ensinar não se restringe ao domínio do conteúdo de ensino pelo professor, tampouco prescinde de conhecimentos específicos, quando se trata de integrar tecnologias digitais ao processo de ensino e aprendizagem.

Pelos atributos que lhe são próprios, o TPACK vem, hoje, ao encontro das novas práticas do aluno em sala de aula, como fotografar a lousa e seu conteúdo, gravar em áudio a aula e/ou as explicações do professor, fazer anotações em bloco de notas digital, realizar pesquisas em tempo real, pela Internet, consultar dicionário e gramática on-line etc. Conforme salienta Kenski (2014), a tecnologia digital elimina fronteiras de tempo e espaço, e a sala de aula não está isenta desse contexto. Considerando esta realidade, para mudar a relação do professor com as tecnologias digitais, é preciso começar pelos conhecimentos que moldam a sua forma de pensar e, por conseguinte, de agir, diante das TDIC.

$\mathrm{Na}$ educação, as tecnologias são tratadas de diferentes modos. Segundo Chaib (2002), subjacentes a esse tratamento estão representações sociais identificadas como otimista, realista e pessimista. $\mathrm{O}$ professor otimista associa à tecnologia novas possibilidades, concebendo-as como facilitadoras e encarando-as como desafio; acredita que deve ter o domínio das mesmas e demonstra interesse por elas. Por sua vez, o realista reconhece o potencial e, ao mesmo tempo, os limites das tecnologias; aceita-as, mas não está convencido de sua contribuição; entende que é preciso aprender a controlar a máquina, como se faz com qualquer recurso tecnológico. Já o pessimista associa a tecnologia a riscos e a enxerga como ameaça; avesso a mudanças, teme a tecnologia e suas consequências nas relações humanas; acredita que seu uso leva à perda do contato humano e da capacidade de aprendizagem do aluno, inibindo sua iniciativa e criatividade.

Os princípios epistemológicos do professor são determinantes em sua prática pedagógica, podendo tanto conferir à tecnologia o papel de um recurso qualquer quanto de uma ferramenta mediadora voltada à aprendizagem. Esses princípios carregam elementos do "triângulo interativo", explicitado por Coll, Mauri e Onrubia (2010, p. 85-86) nos seguintes termos: "o que define o tipo de uso que se dá às TIC é sua posição na rede de relações que se estabelecem entre os três elementos do triângulo interativo - professor, estudantes e conteúdo - enquanto são realizadas as atividades de ensino e aprendizagem na sala de aula". Tais elementos assumem papéis distintos no interior dos paradigmas instrucionista e construcionista, o primeiro caracterizado por traços como aluno passivo, professor transmissor de informações e tecnologia para "fazer mais do mesmo"; o segundo, por aluno ativo, professor facilitador da aprendizagem e tecnologia para "fazer o que antes não se fazia sem ela" (PAPERT, 1992).

Segundo Masetto (2012), a configuração desses elementos na aula universitária varia conforme o paradigma que a fundamenta, e este pode ser voltado ao ensino ou à aprendizagem. Salienta o autor que é preciso passar do primeiro para o segundo, sem incorrer em esvaziamento de conteúdo ou perda de importância do professor, a quem cabe decidir os meios e os fins do ato pedagógico.

As premissas de que cada paradigma aponta um papel para o professor no processo educativo e de que a escola não é uma ilha isolada da sociedade que constitui e pela qual é constituída levam-nos a resgatar Gramsci (1995) e sua perspectiva do professor como agente da mudança, a qual sugere o abandono da "zona de conforto" (PENTEADO; SKOVSMOSE, 2008) que aliena e ilude

\footnotetext{
${ }^{8} \mathrm{Da}$ confluência entre o Conhecimento Pedagógico (Pedagogical Knowledge - PK) e o Conhecimento do Conteúdo (Content Knowledge - CK) surge o Conhecimento Pedagógico de Conteúdo (Pedagogical Content Knowledge - PCK), o mesmo ocorrendo entre o Conhecimento Tecnológico (Technological Knowledge - TK) e o PK — que dão origem ao Conhecimento Pedagógico da Tecnologia (Technological Pedagogical Knowledge - TPK) - e entre o TK e o CK, que constituem o Conhecimento Tecnológico de Conteúdo (Technological Content Knowledge - TCK). 
quanto ao futuro de uma educação que parece não mais atender aqueles aos quais se destina. A educação hoje necessita de um "professor aprendente" (PONTE, 2000), que não se intimida ao perceber que sabe menos que os alunos sobre determinada tecnologia e aprende junto com eles, mobilizando-os para esse fim. De outro modo, como conciliar práticas pedagógicas que datam do trivium e do quadrivium (MANACORDA, 2010) com práticas sociais que incluem tecnologias móveis de conexão sem fio (TMSF) (ALMEIDA, 2013; ALMEIDA; VALENTE, 2016)?

Conforme sugere esse questionamento, a educação não para no tempo. Partindo do pressuposto de que toda prática pedagógica é também social, voltamos o foco para o aluno nascido na Era Digital (PALFREY, 2011), que parece confirmar a premissa de Belloni (2009) de que, ainda que a escola seja a mesma e mantenha velhas práticas, o aluno mudou e anseia por uma relação diferente com essa instituição. A esse respeito, cabe a ressalva de que, em sala de aula, nem todos os alunos se mostram à vontade ou se saem bem em atividades com tecnologias, o que levou Duran, Amiel e Castro (2014, p. 57) a questionarem se podemos chamar "toda uma geração de alunos como "nativos digitais".

Como constatou Sousa (2010), para compreender o modo como se comporta o aluno em atividades com tecnologias em sala de aula, é preciso atenção ao que elas representam para ele fora desse local e à expectativa que ele tem sobre a aula, entre outros fatores. Apesar de toda a familiaridade do aluno com as tecnologias, é possível encontrar aquele que não sabe fazer uso de uma planilha Excel, por exemplo, ou não vislumbra a possibilidade de uso pedagógico de uma tecnologia que ele utiliza para outros fins. Essas situações, contudo, não negam a constituição do aluno como sujeito social imerso numa cultura digital e midiática (SANTAELLA, 2003), o qual não se pode forçar a aprender ou pretender que aprenda por meio de atividades criadas para um aluno de outra época (TARDIF, 2002).

\section{A FORMAÇÃO PARA O USO DAS TDIC: DO PROJETO À SALA DE AULA}

Partindo de resultados que permitiram constatar que dois cursos de Licenciatura em Matemática de uma universidade pública do estado de São Paulo, identificados como CM1 e CM2, previam a formação para o uso das TDIC em seus projetos pedagógicos, investigamos, primeiramente, se essa formação existia na prática e se era realidade no curso. Num segundo momento, analisamos como essa formação se configurava e se ela ocorria conforme estava previsto no projeto pedagógico.

Nos cursos investigados, a articulação entre disciplinas é o meio adotado para promover essa formação. No CM1, essas disciplinas são Introdução à Computação, Laboratório de Computação e Noções de Ensino de Matemática Usando o Computador - a primeira obrigatória, as duas últimas optativas. No CM2, Ensino de Matemática por Múltiplas Mídias, Introdução à Ciência da Computação I e Introdução à Programação de Computadores, todas obrigatórias.

Nos dois cursos, essas disciplinas são organizadas em blocos ou núcleos, como previsto no Programa de Formação de Professores (PFP) da universidade focalizada, tomado como referencial pelos cursos de licenciatura para a elaboração de seus projetos pedagógicos. De acordo com o PFP (SÃO PAULO, 2004), quatro blocos constituem a organização curricular mínima: Formação Específica (Bloco I), Iniciação à Licenciatura (Bloco II), Fundamentos Teóricos e Práticos da Educação (Bloco III) e Fundamentos Metodológicos do Ensino (Bloco IV).

Além dessa organização, os cursos têm como característica a composição híbrida da carga horária, com disciplinas constituídas por mais de um dos componentes curriculares previstos na Resolução do Conselho Nacional de Educação/Conselho Pleno (CNE/CP) nº. 2/2002 (BRASIL, 2002). Por exemplo, das 120 horas de Metodologia do Ensino de Matemática I, 60 são atribuídas ao estágio curricular supervisionado, 40 aos conteúdos curriculares de natureza científico-cultural e 20 à prática como componente curricular. Do mesmo modo, das 165 horas de Prática de Ensino de Matemática I, atribuem-se 150 ao estágio curricular supervisionado e 15 à prática como componente curricular.

Ainda segundo os projetos pedagógicos, para promover a formação para o uso das TDIC, além da articulação entre disciplinas, os cursos apostam na infraestrutura favorável das instituições de ensino, com laboratórios didáticos e de Informática, equipamentos e máquinas, Internet etc. 
Com relação ao corpo docente, os professores que atuam nos cursos são lotados em departamentos diversos, como por exemplo, Computação, Física e Educação, dentre outros. Todos os entrevistados são contratados em regime de Dedicação Exclusiva (DE), havendo variação entre eles quanto à experiência na profissão; alguns, como P14, em exercício há menos de dez anos, outros, como P2, há mais de quinze anos.

No que tange à articulação entre disciplinas prevista nos projetos pedagógicos, ela não se confirmou nos cursos. No CM1, a disciplina optativa Laboratório de Computação estava inativa e, como tal, não existiu para os alunos concluintes participantes do estudo. No CM2, o mesmo ocorreu com a disciplina obrigatória Introdução à Ciência da Computação I. As demais disciplinas envolvidas na articulação não mantinham relações entre si. Uma explicação para a ausência de articulação poderia ser a fragmentação apontada por Santos (2002), verificada na organização do currículo por disciplinas, no interior das quais o conhecimento tende a ser tratado de modo isolado, por meio de uma prática pedagógica que separa o conteúdo do ensino propriamente dito, conferindo lugares distintos à teoria e à prática no processo formativo.

Essa organização, geralmente pautada na racionalidade técnica (PÉREZ GÓMEZ, 1997), aliada a fatores como o rol de atividades que competem ao professor desempenhar na universidade, dificulta a comunicação entre os professores que atuam em um mesmo curso, especialmente quando são lotados em departamentos distintos, caso de Ensino de Matemática por Múltiplas Mídias, ministrada por P2 e P3, ambos do Departamento de Matemática, e Introdução à Programação de Computadores, ministrada por P8 e P10, do Departamento de Matemática Aplicada e Estatística, arroladas na articulação prevista no projeto pedagógico do CM2.

Salvo exceções, o modelo de formação a partir do qual os cursos de licenciatura são estruturados prevê justaposição e não articulação entre disciplinas, primando por teoria antes e aplicação dela depois, ao fim do curso. Nem mesmo a constituição híbrida da carga horária de uma disciplina, composta por componentes curriculares distintos, é capaz de alterar, por si só, esse quadro.

Outros fatores que poderiam explicar a referida falta de articulação são a distância que separa o que está previsto em documentos, tais como projeto pedagógico e programa de ensino do trabalho pedagógico, e o que é efetivamente realizado em sala de aula (GATTI; BARRETTO, 2009), assim como o lugar secundário ocupado pelo ensino e, por conseguinte, pelas atividades de ensino na universidade (CANDAU, 1997).

Ao serem indagados sobre a articulação entre disciplinas, nenhum professor se referiu ao projeto pedagógico do curso ou à articulação nele prevista, destinada a formar o egresso para o uso das TDIC. Desse modo, a articulação apontada nos projetos não se confirmou na prática, emergindo das entrevistas o apresentado no Quadro 1.

Quadro 1 - Formas de articulação nas disciplinas dos cursos investigados

\begin{tabular}{|l|c|l|}
\hline \multicolumn{1}{|c|}{ Curso } & \multicolumn{1}{|c|}{ Articulação } & \multicolumn{1}{c|}{ Descrição } \\
\hline CM1 & $\begin{array}{c}\text { Entre disciplinas de } \\
\text { Metodologia }\end{array}$ & $\begin{array}{l}\text { Entre Metodologia do Ensino de Matemática I e Metodologia do Ensino de } \\
\text { Matemática II. }\end{array}$ \\
\hline CM1 e CM2 & Metodológica & $\begin{array}{l}\text { Circunscrita ao interior de uma disciplina, realizada pelo professor durante a } \\
\text { aula, quando traz conceitos de outras disciplinas, relacionando-os. }\end{array}$ \\
\hline CM1 e CM2 & Histórica ou estrutural & $\begin{array}{l}\text { Entre disciplinas ligadas por pré-requisito, o aluno somente se matricula em } \\
\text { uma se tiver cursado a(s) outra(s). }\end{array}$ \\
\hline CM2 & $\begin{array}{l}\text { Entre disciplinas consolidadas, que dispensam o diálogo entre os } \\
\text { professores, pois quem as assume já sabe o que ministrar. } \\
\text { de Matemática I e II e } \\
\text { Ensino de Matemática } \\
\text { por Múltiplas Mídias }\end{array}$ & $\begin{array}{l}\text { No decorrer do curso, os conhecimentos adquiridos em uma disciplina são } \\
\text { empregados em outra. }\end{array}$ \\
\hline
\end{tabular}

Fonte: Elaboração própria. Corpus da entrevista com os professores.

Nenhuma das articulações apontadas pelos entrevistados tem como finalidade a formação do egresso para o uso das TDIC. Nem mesmo a sugerida por P2 e P3, entre as disciplinas Prática de Ensino de Matemática I e II e Ensino de Matemática por Múltiplas Mídias. Conforme frisou P2, 
somente a última "tem como foco articular as práticas de ensino com o uso de tecnologias, especificamente", corroborada por P3: "disciplina para o uso de tecnologias mesmo eu acredito que a gente tem apenas a Múltiplas Mídias”.

Assim, das três disciplinas apontadas no projeto pedagógico de cada curso como aquelas que, articuladas, promoveriam a formação para o uso das TDIC, uma não existiu para os alunos concluintes. Das outras duas, uma tem como finalidade promover a referida formação, podendo ser ministrada de modos distintos, que variam conforme o professor. Este traço é evidenciado por P3, ao se referir a um semestre em que Ensino de Matemática por Múltiplas Mídias, geralmente assumida por P2 e P3, foi atribuída a outra professora: “[...] o que ela fez? Fez palestras, toda aula foi um professor que veio [...], o que os alunos aprenderam de uso de software? Eles ficaram só na discussão, [...] de que adianta discussão?".

A presença da tecnologia digital na aula foi tomada como indício de formação para o uso das TDIC pelos participantes. Desse modo, para eles, em cada curso, a formação ocorreu em mais de uma disciplina, em situações variadas, nas quais as tecnologias surgiram como tema de discussão ou foram utilizadas pelo professor ou pelos alunos na aula e fora dela. Investigamos as situações apontadas, identificando-as a partir do tipo de conhecimento relacionado às TDIC envolvido em cada uma.

Dessa forma, aquelas que comportaram somente discussão sobre o uso de tecnologias na escola ou tema relacionado a este uso foram classificadas como "aprender sobre o uso de tecnologia". Atividades em que os alunos utilizaram tecnologias para aprender o conteúdo de ensino, seja ele matemático, computacional ou educacional, realizadas na aula ou extraclasse, foram classificadas como "aprender com o uso de tecnologia". Atividades em que o futuro professor utilizou a tecnologia para aprender conteúdos matemáticos, de modo que vivenciasse como ensiná-los com tecnologia na escola básica (perspectiva da simetria invertida), foram identificadas como "aprender a ensinar com o uso de tecnologia". Atividades em que o professor formador utilizou tecnologia(s) na aula, para ensinar, foram classificadas como "ensinar com tecnologia".

Discussão de temas relacionados às tecnologias e apresentação de trabalho pelo aluno sobre tema que envolvesse tecnologias ocorreram, por exemplo, em Didática, como sugere P14, ao discorrer sobre a formação para o uso das TDIC na disciplina por ela ministrada: "houve, quando se falou da relação pedagógica, da cultura escolar, então, em vários momentos, a gente acabou falando do uso de recursos", sendo, também, verificada em Metodologia do Ensino de Matemática, no CM1, e em Prática de Ensino de Matemática, no CM2. Sem pretender negar o valor e o lugar do arcabouço teórico na constituição dos quadros referenciais para a docência, os quais se concebem a partir de Mizukami (1996), a situação descrita leva a resgatar os dizeres de Gatti e Barretto (2009, p. 144), ao indagarem se "disciplinas que apenas discutem, teoricamente, a informática no ensino [...] são suficientes para uma futura prática docente com utilização das novas tecnologias".

Do ponto de vista do TPACK, situações em que o aluno somente aprende sobre o uso de tecnologia não bastam para formar um professor que, efetivamente, saiba utilizá-la para propiciar aprendizagem, conhecendo o potencial e os limites da mesma, ciente de que a docência está em permanente construção. Parafraseando estudiosos da área das Ciências Exatas, ao se referirem à aprendizagem de uma ciência experimental (SANTOS; ALVES; MORET, 2006), o fazer docente não se aprende somente "de ouvido", em especial quando se trata do que poderíamos chamar de "docência 3.0", expressão de nossa autoria, que faz remissão ao conceito de "educação 3.0", de Fava (2014) e, assim como aquele, situa o objeto no tempo, permitindo vislumbrar um fazer docente que não é atemporal e impermeável a mudanças, mas que, sensível às mesmas, busca reinventar-se.

No interior de disciplinas do CM1 e do CM2, além de discussões sobre temas relacionados às tecnologias, nas quais, não sendo o foco, essas últimas compareciam de modo marginal, os alunos vivenciaram situações voltadas a aprender sobre a máquina, seu funcionamento e suas linguagens, conhecimento, esse, necessário, porém não suficiente para o uso das tecnologias digitais, conforme esclarecem Cibotto e Oliveira (2017). Também nesse caso as atividades formativas podem se restringir à abordagem teórica, como sugere a professora de Introdução à Computação, ao dizer: "A disciplina é teórica, só tenho aula teórica, mas no início do semestre acho que teve umas duas aulinhas que o 
monitor dava na salinha lá de computadores, explicando como usar as coisas básicas do computador e mais o compilador" (P12).

Segundo P10 e P13, nas disciplinas computacionais, o futuro professor aprende sobre a tecnologia e com o uso dela. Como disse um professor de Introdução à Programação de Computadores, "um dos trabalhos que a gente costuma passar para os alunos é exatamente manipulação de matrizes, fazer programas computacionais para a manipulação de matrizes, então acredito que isso ajude os alunos a aprender matemática" (P10). Do ponto de vista da simetria invertida, essa experiência poderia repercutir satisfatoriamente na futura prática pedagógica do aluno, uma vez que, já na formação inicial, ele aprende do modo que se espera que venha a ensinar posteriormente na Educação Básica, ressalvado o fato de que nas disciplinas Introdução à Computação e Introdução à Programação de Computadores o foco não está na formação de professores, tampouco na aprendizagem do conteúdo matemático.

Além disso, como disseram P12 e P13, nessas disciplinas, atividades envolvendo matemática e uso de tecnologias pelo aluno eram, em geral, extraclasse: “[...] essa disciplina pressupõe muito trabalho extraclasse ligado à atividade de programação, que são os nossos exercícios-programa, então os alunos devem passar bastante tempo realizando isso, aí sim em laboratórios, em casa, alguma coisa assim" (P13). Atividade extraclasse envolvendo o uso de tecnologias pelos alunos também ocorreu na disciplina Estrutura e Funcionamento do Ensino Fundamental e Médio, como indica P9: "Os vídeos eles têm que editar, porque eles não podem só pegar o vídeo e trazer, eles têm que colocar vídeos de no máximo três a cinco minutos".

Retomando a análise das situações envolvendo TDIC nas disciplinas computacionais, acrescentamos o fato de serem ministradas em mais de um curso de licenciatura e também em cursos de bacharelado, sem sofrer alterações em função da "audiência", nome atribuído por P13 a cada turma: "eu não dei nada diferente voltado para a turma da licenciatura, a disciplina foi dada assim pensando no que eu dou para outros cursos, não fiz nada em especial por ser licenciatura" (P12). Nesse ponto, divergem os professores de Introdução à Computação, pois, segundo P13: "Os conceitos centrais são os mesmos, os conceitos fundamentais são os mesmos, mas o jeito que a gente ministra a disciplina se adapta a cada audiência".

Ampliando o conceito "aprender a ensinar", verificado em Mizukami (1996) e Mizukami et al. (2002), investigamos "aprender a ensinar com o uso de tecnologias". Nos cursos pesquisados, essas situações despontaram nas disciplinas Ensino de Matemática por Múltiplas Mídias e Noções de Ensino de Matemática Usando o Computador. Segundo P3, em Ensino de Matemática por Múltiplas Mídias, "o trabalho final é que eles usem três mídias para falar de determinado conteúdo". De acordo com P7, em Noções de Ensino de Matemática Usando o Computador, "O trabalho final dos alunos foi desenvolver um curso inteiro, para ser aplicado a alunos 'reais' do Ensino Fundamental e Médio". Em ambas, o aprender a ensinar com o uso de tecnologia compunha o conteúdo programático e os objetivos.

Ao apontado, cabem ressalvas. A primeira delas diz respeito ao local de uso da tecnologia pelos alunos, nem sempre a sala de aula, tampouco a aula, e ao fato de a atividade extraclasse, como o nome diz, não alterar a prática pedagógica vivenciada pelo estudante na aula (VALENTE, 1993). A segunda ressalva refere-se ao enfoque em mídias, inclusive em "outras mídias mais antigas" (P2), e não apenas em TDIC, em Ensino de Matemática por Múltiplas Mídias. Considerando que as mídias, em geral, compõem o conjunto mais abrangente das TIC, como esclarece Afonso (2002), nem toda a carga horária da disciplina é dedicada ao tratamento das TDIC. Além disso, na perspectiva do TPACK (CIBOT'TO; OLIVEIRA, 2017), cumpre refletir sobre os conhecimentos oriundos do enfoque nas mídias, as quais não necessariamente comportam o triângulo interativo, anteriormente referido (COLL; MAURI; ONRUBIA, 2010). A terceira e última ressalva é relativa à perspectiva de que se aprende a ensinar com o uso de tecnologia por meio da produção de material didático para a Educação Básica, inferida de Noções de Ensino de Matemática Usando o Computador. Assim enunciada, essa perspectiva contraria a natureza do fazer docente, conforme apontado por Mizukami (1996) e Schön (1997), marcada por imediaticidade, imprevisibilidade, complexidade e diversidade, o que a distingue da 
ação de produzir material para a educação. Os conhecimentos envolvidos em uma e outra ação são diferentes, embora possam convergir em algum ponto.

$\mathrm{Na}$ perspectiva de Santos (2010, p. 23), a produção de material didático com tecnologias digitais pelo estudante do curso de licenciatura pode ser vista como um primeiro passo na direção da constituição de um "professor-autor" e não apenas usuário das TDIC no processo de ensino e aprendizagem, levando-se em conta as condições em que ocorre - por exemplo, somente no interior de uma disciplina, com carga horária de 60 horas, no decorrer de todo o curso superior.

Analisada à luz de Marco (2009), que propôs a alunos de um curso de Matemática que produzissem material didático com tecnologias para a escola básica e, além disso, planejassem a aplicação do mesmo no Ensino Fundamental ou Ensino Médio, o vivenciado no interior de Noções de Ensino de Matemática Usando o Computador é limitado, em termos de conhecimentos para a docência, quando se trata de aprender a ensinar com o uso de tecnologia.

$\mathrm{Na}$ disciplina Metodologia do Ensino de Matemática, verificamos a ocorrência de uma situação favorável à promoção do aprender a ensinar com o uso de tecnologia, enunciada por P4 conforme se segue: "cada aluno escolhe um tema para preparar, vamos dizer assim, como eles abordariam determinado assunto com alunos de determinado ano do Ensino Fundamental ou Médio, então nesse elenco de possibilidades muitas vezes aparece o tema do uso da tecnologia". Contudo, para existir na disciplina e no curso, essa situação depende do professor, uma vez que ela é parte da metodologia "dele", isto é, adotada por ele. Depende também dos alunos, que podem não escolher o tema "uso de tecnologia na escola", por falta de conhecimentos prévios que facilitem desenvolvê-lo ou por serem detentores de uma visão refratária à incorporação das TDIC à educação.

Além das situações analisadas, constatamos outras, identificadas na pesquisa como "ensinar com tecnologia", apontadas pelos alunos e pelos professores como parte da formação para o uso das TDIC, que consistem somente no uso da tecnologia pelo professor na aula. Das situações apuradas nessa categoria, destacam-se as que evidenciam o que nomeamos "conflito epistemológico", que se instala quando o professor pretende facilitar a compreensão do conteúdo pelo aluno (a aprendizagem concebida conforme a perspectiva cognitivista ou a construcionista) por meio de práticas que pressupõem memorização e reprodução do conteúdo de ensino e mantêm o aluno na condição de observador e ouvinte (a aprendizagem concebida conforme a perspectiva tradicional ou a instrucionista).

Uma dessas situações é descrita por P11: "a gente entra no site do PNUD, Programa das Nações Unidas para Desenvolvimento, em tempo real, na sala tem rede normalmente, então vê lá a tabela de IDH, senão ninguém entende a aula". As ações dos alunos nessa aula expositivo-ilustrada pela tecnologia digital consistem em observar ("a gente vê lá"), ouvir e, eventualmente, falar. Trata-se, como disse o professor, de mostrar aos alunos o que antes teriam que imaginar a partir de sua fala, nisto consistindo a contribuição da tecnologia na aula.

Situação análoga é descrita por P10:

[...] eu particularmente gosto de fazer nesses cursos de programação todos os exemplos que a gente chama de in real time, quer dizer eu faço o programa na frente dos alunos para que vejam não somente como fazer a programação, mas também ver que eu erro e como eu conserto os erros da minha própria programação, para ensiná-los a encontrar erros.

Se considerarmos os elementos apontados por Coll, Mauri e Onrubia (2010), a saber, aluno, professor e conteúdo, verificamos que, em ambas as situações, os papéis do professor e do aluno coincidem, permitindo-nos inferir o papel atribuído à(s) tecnologia(s).

Outros usos em que os papéis do professor e do aluno não se alteram pela presença das tecnologias foram descritos pelos entrevistados. Um deles se encontra nas palavras de P11: "nas aulas eu utilizo regularmente PowerPoint, busco um site ou outro para ilustrar uma coisa que está sendo feita, mas, assim, usou, depois desligo e continuo a aula". O outro se extrai dos dizeres de P10: "você entrar num site desse e mostrar para os alunos as diversas variações de certos algoritmos e coisas do 
tipo, a Internet certamente é uma das tecnologias que a gente usa, a outra, as aulas com PowerPoint e coisas desse tipo, mas isso é bastante comum”.

\section{Por que usar tecnologias, se tanto faz ensinar com ou sem elas?}

Das falas dos professores formadores sobre o uso que eles próprios fazem das tecnologias na aula e do que disseram as coordenadoras dos cursos a esse respeito, destacamos aspectos inquietantes, que geram reflexão. Um deles é a fragilidade da formação do professor universitário para fazer uso pedagógico de tecnologias emergentes, determinante na relação que mantém com as TDIC.

[...] os alunos sabem muito mais tecnologia do que eu, não tive uma formação específica, como também, se eu pensar na minha condição de professor, não tive uma formação para ser professor de metodologia, mesmo na época que eu era estudante do curso de Matemática, eu não trouxe nada para hoje, para as aulas, então é uma maneira solitária de fazer ou de tirar dúvidas etc. (P4)

Questões anteriores e mais amplas do que a falta de preparo do professor formador para o uso das TDIC na aula universitária despontam dos dizeres de P4, notadamente: a falta de formação para o exercício da docência e a falta de mecanismos que auxiliem esse professor nas atividades de ensino, quando ele necessitar, especialmente em caso de implementação de práticas inovadoras para ele, porque diferentes das usualmente realizadas em sala de aula.

Ao encontro do que disse P4 sobre a "maneira solitária de fazer ou de tirar dúvidas", vêm as palavras de $\mathrm{C} 1$, relativas à falta de valorização de iniciativas que buscam ir além das usuais práticas pedagógicas vigentes nos cursos superiores.

Nós tivemos algumas tentativas, mas as dificuldades maiores foram a questão do tempo e da valorização mesmo da atividade do professor. O professor vai se sentindo pouco valorizado e aí ele verifica que tem um trabalho maior, que demanda mais tempo, mais dedicação e não tem uma valorização compatível e aí acabou que ele foi se desligando dessa prática. (C1)

As falas de $\mathrm{C} 1$ e de P4, de cursos distintos, parecem convergir no que diz respeito ao professor se encontrar sozinho na tarefa de ensinar utilizando tecnologias digitais na aula universitária, iniciativa que se perde em meio às agruras de um ambiente "impermeável" ao novo (MARCOLLA, 2008). Sem pretender vitimizar o docente, urge encontrar meios de valorizar e apoiar novas práticas pedagógicas no Ensino Superior, não porque incluem tecnologias digitais, mas pela ousadia de inovar e priorizar o ensino na universidade.

O uso das tecnologias pelo professor formador e o papel que atribui a elas na aula pode influenciar o que o futuro professor pensa sobre o lugar das tecnologias no processo de ensino e aprendizagem, reforçando ou ressignificando o que ele vivenciou na Educação Básica (PIRES, 2002; ROSADO, 1998). Embora o impacto da formação inicial sobre as concepções de ensino e aprendizagem dos estudantes seja limitado, como alertam Mizukami et al. (2002), ele existe e adquire relevância quando se pressupõe que a licenciatura é a base da profissionalização docente (GATTI; BARRETTO; ANDRE, 2011).

De modo geral, a análise das situações descritas permitiu constatar que, em cada curso, os alunos concluintes vivenciaram situações em que apenas discutiram o uso de tecnologias na escola, em disciplinas como Didática e Metodologia do Ensino de Matemática. Concomitantemente, também vivenciaram outras, em que aprenderam sobre a máquina e suas linguagens, utilizando a tecnologia na aula e fora dela, para aprender conteúdos curriculares do Ensino Superior, nas disciplinas Introdução à Computação, Introdução à Programação de Computadores e Estrutura e Funcionamento do Ensino Fundamental e Médio.

De todas as situações apontadas pelos participantes, as que envolveram aprender a ensinar com o uso de tecnologias estiveram presentes em Ensino de Matemática por Múltiplas Mídias e Noções de Ensino de Matemática Usando o Computador, disciplinas de cursos distintos. Nessa última, 
o enfoque esteve em produzir materiais didáticos, como softwares educacionais, para o Ensino Fundamental e o Ensino Médio. À luz dos pressupostos de Cibotto e Oliveira (2017), assim configurado, o rol de conhecimentos incrustado nas situações, em geral, mesmo reunido, não dá conta do TPACK, em toda a sua complexidade e abrangência.

Retomando a pergunta verificada no título desta seção, a saber, "por que usar tecnologias, se tanto faz ensinar com ou sem elas?", do ponto de vista das políticas de valorização profissional, tanto faz ensinar com ou sem tecnologias; mas, na perspectiva da constituição do ser social chamado "aluno" e do profissional que atende pelo nome de "professor", o uso das TDIC pode fazer a diferença.

Observando atentamente o enunciado da pergunta, indagamos "tanto faz" para quem? Para o aluno, a diferença está em se constituir profissionalmente no bojo de uma formação em que as TDIC são tratadas como mediadoras no processo de ensino e aprendizagem. Essa perspectiva aponta para a reconfiguração da formação inicial do professor no cenário das TMSF e questiona se, a exemplo da prática pedagógica, também a formação inicial não estaria "parada no tempo".

\section{DAS PRÁTICAS ÀS CONCEPÇÕES QUE AS (IN)FORMAM}

As concepções foram analisadas quanto ao posicionamento dos participantes diante da inserção de tecnologias na educação, sendo identificadas como otimista, realista ou pessimista, e à abordagem pedagógica subjacente à prática, podendo ser instrucionista ou construcionista e tradicional ou cognitivista, essas últimas marcando a ausência das TDIC no processo de ensino e aprendizagem. Em caso de falta de elementos para classificação, a concepção foi considerada indefinida.

Questionados sobre o que pensavam acerca do uso de tecnologias na escola, os futuros professores voltaram sua atenção para as dificuldades de implementação na Educação Básica, a exemplo de A3T2, "Há recursos, porém é necessário pesquisar para aplicá-los e saber se há disponibilidade destes recursos nas escolas públicas", e de A1T3, que respondeu:

[...] devido a problemas de infraestrutura, principalmente nas escolas públicas, e a dificuldade dos alunos encararem o computador como uma ferramenta de estudo, o uso de tecnologias para o ensino é muito mais restrito e deve ter um planejamento muito mais cuidadoso, considerando variáveis além das pedagógicas. Isso porém não torna o uso de tecnologia impossível, somente mais restrito devido as condições enfrentadas.

As dificuldades de uso das tecnologias no processo de ensino e aprendizagem da escola básica também são objeto de atenção de alguns professores do CM1 e do CM2. A esse respeito, disse P11: "o que é ruim é a condição de trabalho do professor, ele não tem tempo, em geral, na escola básica, para preparar, para ir lá para a sala fazer com os alunos, o tempo de preparação é muito escasso, porque ele dá muitas aulas". Nessa direção, vem a fala de P3: "a gente leva para a escola, mas a Internet das escolas é tão ruim, as escolas têm vinte computadores, a gente vai com uma proposta, só pode ligar dez, porque, se ligar os vinte, cai a energia, não funciona nenhum”. Essas falas são corroboradas por P10: "as pessoas ficam hoje em dia botando muita pressão, 'o professor tem que usar', mas os recursos na escola pública não estão tão disponíveis assim como as pessoas pensam”.

Os fragmentos citados no parágrafo anterior carregam indícios da concepção realista e vêm ao encontro do apontado pela literatura educacional sobre as dificuldades de implementação das TDIC na escola básica (PENTEADO, 2000; SANTOS, 2017). Ao tratar desse assunto, cabe atenção aos argumentos empregados pelos professores para aderir ou refutar as tecnologias na Educação (VALENTE, 1993), os quais compõem um debate mais amplo, ainda hoje presente nessa área (HOWARD; MOSEJKO, 2015; HORN, 2017).

Sobre o uso e a apropriação das TIC no processo educativo das escolas brasileiras, uma pesquisa realizada pelo Centro Regional de Estudos para o Desenvolvimento da Sociedade da Informação aponta como desafios a conectividade, a infraestrutura e uma "cultura escolar mais restritiva em termos de uso desses recursos" (CETIC, 2018, p. 127), o que, do ponto de vista do 
referido estudo, "não significa que as tecnologias não estejam presentes nos espaços de ensino e aprendizagem, inclusive influenciando o cotidiano e o currículo das escolas" (CETIC, 2018, p. 127). De acordo com essa pesquisa, "No geral, professores, coordenadores e diretores de escolas públicas possuem uma visão positiva quanto ao uso das tecnologias no âmbito educacional" (CETIC, 2018, p. 129).

Apesar do apontado pelo referido Centro (CETIC, 2018), a falta de motivação dos futuros professores com relação às possibilidades de uso das tecnologias digitais na escola beira ao desencanto. Eles questionam o porquê de serem formados para usar tecnologias na aula, se na escola não há condições para esse fim. As dificuldades de uso das TDIC compõem a concepção realista verificada nas respostas de oito $(80 \%)$ dos dez alunos do CM2 e sete (46,7\%) dos 15 do CM1. A essa concepção se contrapõe outra, a otimista, verificada nos pontos em que discorrem sobre o potencial das tecnologias para aprendizagem, presente nas respostas de dois $(20 \%)$ dos dez alunos do CM2 e oito $(53,3 \%)$ dos 15 do CM1, sinalizando que a relação dos alunos do curso de licenciatura com as TDIC pode ser promissora, especialmente no caso do CM1. Entretanto, conforme verificado adiante, no que concerne ao uso das tecnologias no processo de ensino e aprendizagem, as concepções tradicional e instrucionista sobressaem entre os alunos desse curso.

As referidas dificuldades são retomadas pelos alunos concluintes, quando informam como ocorreria o uso de tecnologias em suas futuras aulas. Das 18 ocorrências apuradas no CM1, sete $(38,9 \%)$ correspondem à falta de infraestrutura, seis $(33,3 \%)$ a questões relativas aos alunos (desatentos, resistentes, turma numerosa), quatro $(22,2 \%)$ à falta de apoio da gestão, uma $(5,6 \%)$ à falta de tempo. Das 21 ocorrências apuradas no CM2, dez $(47,6 \%)$ correspondem à falta de infraestrutura, quatro $(19 \%)$ à falta de formação de professores, quatro (19\%) à dificuldade de lidar com os alunos (dispersos, indisciplinados), duas $(9,5 \%)$ à falta de tempo e uma $(4,8 \%)$ à falta de apoio da gestão.

O questionário ainda solicitou aos alunos que esboçassem uma aula de Matemática com tecnologias digitais. A análise leva em conta as condições em que realizaram essa atividade. Do ponto de vista da abordagem pedagógica, em cada turma, as concepções variam entre instrucionista e construcionista, prevalecendo esta última no CM2. Também constatamos ocorrências da tradicional e da cognitivista, prevalecendo a primeira no CM1, curso no qual dois alunos não esboçaram a aula, e um escreveu que não pretendia ser professor.

De modo específico, das 12 ocorrências apuradas no CM1, seis (50\%) sugerem a concepção tradicional, três $(25 \%)$ a instrucionista, duas $(16,7 \%)$ a cognitivista e uma $(8,3 \%)$ a construcionista. Das 26 ocorrências apuradas no CM2, sete $(26,9 \%)$ sugerem a concepção construcionista, seis $(23,1 \%)$ a indefinida, cinco $(19,2 \%)$ a cognitivista, quatro $(15,4 \%)$ a tradicional e quatro $(15,4 \%)$ a instrucionista. Nesse curso, os percentuais relativos à indefinida, à tradicional e à instrucionista totalizam 53,9\% e, juntos, parecem indicar que os alunos concluintes se encontram em uma fase de transição de um paradigma a outro, haja vista a porcentagem relativa à indefinida, culminando no que denominamos "conflito epistemológico".

A aula com tecnologias esboçada pelos alunos aponta para o conflito epistemológico também verificado com os professores P10 e P11. No caso dos alunos, esse conflito manifesta-se entre o papel conferido ao professor na aula com tecnologia e a metodologia adotada para desenvolvê-la; no caso dos professores, entre os objetivos e a metodologia da aula com TDIC. Estes últimos pretendem propiciar aprendizagem nos moldes cognitivistas por meio de práticas de cunho instrucionista. Não estamos aqui dizendo que uma mesma aula não comporte princípios epistemológicos distintos ou que, comportando, sejam inconciliáveis, algo que poderia ser visto, inclusive, como indício de transição da passagem de um paradigma a outro (MASETTO, 2012), mas tão somente chamando atenção para a necessidade de coerência na relação entre os meios e os fins do trabalho educativo.

Nessa perspectiva, uma mesma aula pode conter atividades orientadas tanto por princípios da abordagem tradicional quanto da cognitivista, por exemplo, se esta configuração atender aos objetivos do trabalho pedagógico. Contudo, nesse caso, é preciso atenção ao apontado por Mizukami (1986) e Moreira (2011) sobre as concepções de educação, de sociedade etc. vinculadas a esse trabalho. Em caso de combinação de práticas sustentadas por princípios epistemológicos distintos, o que 
prevalece? Além disso, é preciso identificar essa combinação na aula, pois, não sendo intencional, tende a evidenciar fragilidades.

Em suas respostas, os alunos mostraram-se confusos quanto ao que muda e ao que permanece na aula, quando ela é realizada com tecnologias, o que poderia ser explicado pelo fato de não terem vivenciado aulas com tecnologias digitais ou terem vivenciado a subutilização dessas últimas na Educação Básica, experiência que pode ser ressignificada ou reforçada no curso superior. Tanto é assim que, questionados se o ensino ao qual foram expostos antes do ingresso na universidade poderia ser tomado como referencial para a sua futura prática pedagógica com TDIC, dos oito alunos da T1, sete $(87,5 \%)$ responderam que não, o mesmo ocorrendo com quatro $(57,1 \%)$ dos sete alunos da T2 e sete $(70 \%)$ dos dez alunos da T3.

Sobre a subutilização das tecnologias, disse P11: "Não há muita condição, então [o professor] usa na sala de aula e isso é uma ilustração que todos estão vendo, assistindo ali. Claro que isso é uma parte, ir para o laboratório é para cada um fazer, que é mais interessante, mas aí depende do número de alunos". Para esse professor, o uso que ele faz de tecnologias na aula poderia ser diferente, se a infraestrutura da universidade assim o permitisse. Em termos de infraestrutura, a realidade retratada por P11 não se estende ao CM2, quando consideramos as palavras de P3: "metade das aulas da disciplina a gente faz no laboratório, que tem um computador para cada aluno, obviamente, porque não tem como você ensinar o aluno trabalhar com tecnologias, se você não leva ele no lugar onde tem o computador".

Analisado à luz das TMSF, que acompanham os alunos a toda hora, em qualquer lugar, inclusive na sala de aula (AMEIDA, 2013), o apontado por P11 e P3, relativamente à necessidade de deslocar os alunos de um local para outro (da sala de aula para um laboratório, por exemplo) que comporte computadores suficientes para todos, perde o sentido. Entretanto, sem pretender aprofundar o assunto, ao tratar de tecnologias móveis e sua utilização na escola, cabe a ressalva de que celular e Internet de uso pessoal do aluno não retiram da instituição de ensino o compromisso de prover os recursos materiais necessários para o processo de ensino e aprendizagem realizado em seu interior.

Passando das concepções dos alunos às dos professores, essas foram inferidas de um corpus constituído por perguntas que os questionaram se se sentiam preparados para ensinar com tecnologias; se sabiam o que é ensinar com tecnologias; o que um professor do Ensino Fundamental e/ou Médio precisa saber para ensinar matemática com tecnologias; o que pensavam sobre o fato de no meio educacional algumas pessoas não se mostrarem convencidas de que tecnologias como o computador pudessem trazer algum benefício ao processo educativo; e, por último, se gostariam de comentar o tema da pesquisa.

Do ponto de vista do posicionamento diante das TDIC na educação, no CM2 prevalece a concepção realista, sendo constatadas ocorrências da pessimista. No que diz respeito à abordagem pedagógica, sobressai a construcionista, com ocorrências da instrucionista. Se consideradas as concepções por professor, um deles (P8) apresenta somente a instrucionista, sendo também o único a fornecer indício da pessimista, e dois (P2 e P9) somente construcionista. No CM1, prevalece a concepção realista, com uma ocorrência da pessimista. No tocante à abordagem pedagógica, há proeminência da instrucionista, com ocorrências da construcionista. Se consideradas as concepções por professor, dois (P6 e P12) evidenciam apenas a instrucionista e um (P11) apenas a construcionista, sendo o único a apresentar a concepção pessimista, além da realista.

Quantitativamente, no CM2, das 14 ocorrências relativas à abordagem pedagógica, nove $(64,3 \%)$ indicam a concepção construcionista e cinco $(35,7 \%)$ a instrucionista, enquanto no CM1, das 11 ocorrências apuradas, oito $(72,7 \%)$ indicam a instrucionista e três $(27,3 \%)$ a construcionista. No que tange ao posicionamento, no CM2, de 13 ocorrências, $11(84,6 \%)$ são atribuídas à concepção realista e duas $(15,4 \%)$ à pessimista, enquanto no CM1, das 15 ocorrências, 14 (93,3\%) indicam a concepção realista e uma $(6,7 \%)$ a pessimista. De modo geral, ao tratar do ensino com tecnologias digitais, os professores formadores apresentam a concepção realista, com variação de um curso para o outro no que diz respeito à abordagem pedagógica subjacente às práticas de uso das TDIC nas disciplinas.

As concepções das coordenadoras dos cursos, por sua vez, foram inferidas a partir de um corpus constituído por respostas a perguntas, tais como: se as tecnologias podem transformar o ensino; 
quem faz uso da tecnologia na aula, o aluno ou o professor; qual o papel do professor em uma aula com tecnologia; se é possível afirmar que toda prática pedagógica que inclui tecnologia é inovadora e o que torna uma prática inovadora. Também foi solicitado que descrevessem uma experiência bemsucedida de uso de tecnologia por um dos professores do curso.

Assim procedendo, verificamos que as coordenadoras apresentam perfis distintos, ao tratarem das TDIC no processo de ensino e aprendizagem. Enquanto C1 evidencia traços das concepções realista e construcionista, C2 oscila entre a realista e a pessimista - esta última, ao tratar de prática inovadora -, a instrucionista e a construcionista. Por sua vez, C3 apresenta as concepções pessimista e construcionista, permitindo entrever uma ocorrência da instrucionista, ao descrever experiências bem-sucedidas de uso de tecnologias por professores do curso.

Quantitativamente, no tocante à abordagem pedagógica, as quatro ocorrências verificadas no corpus fornecido por C1 indicam a concepção construcionista; no corpus de C2, das cinco ocorrências identificadas, três $(60 \%)$ evidenciam a concepção instrucionista e duas $(40 \%)$ a construcionista; quanto à C3, de cinco ocorrências, quatro $(80 \%)$ apontam a concepção construcionista e uma $(20 \%)$ a instrucionista. Com relação ao posicionamento, em C1, as duas ocorrências localizadas indicam a concepção realista; em C2, de três ocorrências, duas $(66,7 \%)$ sugerem a concepção realista e uma $(33,3 \%)$ a pessimista; em C3, a única ocorrência localizada aponta a concepção pessimista.

Enquanto as concepções de C1 vêm ao encontro das verificadas junto aos alunos e professores do CM2, as de C3 não confirmam a realista, a tradicional e a instrucionista apuradas entre os alunos e os professores do CM1, tampouco a otimista verificada junto aos alunos deste curso.

\section{CONSIDERAÇÕES FINAIS}

Conhecimentos como o TPACK devem compor os quadros referenciais para a docência, partindo do pressuposto de que podem fortalecer a formação inicial em cursos de licenciatura, numa época em que a cultura digital e midiática confere ao sujeito social novos modos de pensar e de agir, e da premissa de que toda prática pedagógica é também social, conforme salientam Kenski (2014) e Almeida e Valente (2016).

Nessa perspectiva, tendo como ponto de partida os resultados de uma pesquisa que apontou a presença da formação para o uso das TDIC nos projetos pedagógicos de dois cursos de Licenciatura em Matemática de uma universidade pública do estado de São Paulo, desenvolvemos o estudo apresentado neste artigo. De cunho qualitativo, a investigação abrangeu aplicação de questionário a alunos concluintes e realização de entrevista semiestruturada com professores e coordenadoras de curso, totalizando 41 participantes de duas instituições de uma universidade. O estudo foi norteado pela seguinte questão: como ocorre a formação para o uso das TDIC contemplada nos projetos pedagógicos dos referidos cursos, segundo as concepções inferidas dos dados fornecidos pelos que a protagonizam e as práticas declaradas pelos mesmos?

Em resposta a essa questão, os resultados evidenciam que, em cada curso, a referida formação ocorreu em uma disciplina, a saber, Ensino de Matemática por Múltiplas Mídias no CM2 e Noções de Ensino de Matemática Usando o Computador no CM1, de acordo com o que cada uma pôde propiciar.

No CM1, esse resultado sugere atenção, considerando que Noções de Ensino de Matemática Usando o Computador tem carga horária de 60 horas e é optativa. Além disso, como disse C3, "essa disciplina precisa ser repensada, porque tem muito pouca gente que se dispõe a dá-la e ela ficou então muito com o viés de um único professor". Caberia investigar porque poucos se dispõem a ministrar essa disciplina, considerando que todos os professores do CM1 entrevistados, sem exceção, se mostraram favoráveis à formação dos licenciandos para o uso das TDIC, quando questionados sobre as possíveis contribuições de suas disciplinas para promovê-la.

Ao tratar da formação para o uso das TDIC, nenhum professor ou coordenadora se referiu ao projeto pedagógico ou à articulação nele prevista, voltada a propiciar ao egresso essa formação, a qual não foi confirmada nos cursos. Pelos professores, foram apontadas: articulação metodológica, por pré-requisito, estrutural ou histórica. Da entrevista com as professoras P2 e P3 do 
CM2, despontou a articulação entre as disciplinas Ensino de Matemática por Múltiplas Mídias e Prática de Ensino de Matemática I e II, intencional, porém informal, porque ausente do projeto pedagógico, e dependente dessas professoras para existir no curso, além de ocorrer somente no interior de Ensino de Matemática por Múltiplas Mídias, configurando-se como articulação metodológica (Quadro 1), que ocorre entre conteúdos de disciplinas distintas no interior de uma única, e, não necessariamente, entre disciplinas.

Para os participantes da pesquisa, a formação para o uso das TDIC se estende a disciplinas que não têm a intenção de promovê-la, alojada no conteúdo programático ou na metodologia, prevalecendo esta última. Entretanto, a formação assim configurada não está assegurada aos futuros professores, por não ser intencional e depender do professor da disciplina para existir no curso.

Em atenção a um dos objetivos específicos da pesquisa, que consistiu em investigar situações que, do ponto de vista dos participantes, propiciaram formação para o uso das tecnologias, constatamos que elas ocorreram em disciplinas que os projetos pedagógicos apontam como responsáveis por promovê-la, a saber, Ensino de Matemática por Múltiplas Mídias e Introdução à Programação de Computadores no CM2 e Noções de Ensino de Matemática Usando o Computador e Introdução à Computação no CM1. Essas situações ocorreram também em disciplinas indicadas pelos alunos no questionário, a saber, Análise Crítica de Livros Didáticos, Estrutura e Funcionamento do Ensino Fundamental e Médio e Prática de Ensino de Matemática I e II no CM2; Didática e Metodologia do Ensino de Matemática I e II no CM1. As situações descritas pelos participantes são identificadas conforme se segue: aprender sobre; aprender com; aprender a ensinar com; ensinar com TDIC.

As situações descritas abrangem atividades de discussão sobre o uso de tecnologias na escola (Didática e Metodologia do Ensino de Matemática I e II); uso de tecnologias pelos alunos, dentro e fora da sala de aula, em atividades voltadas a aprender sobre linguagens de programação, que incluem Matemática, a exemplo dos "exercícios-problema" (Introdução à Computação e Introdução à Programação de Computadores); uso de tecnologias pelos alunos para edição de vídeo em atividade extraclasse (Estrutura e Funcionamento do Ensino Fundamental e Médio).

Além dessas, há criação de material didático para alunos do Ensino Fundamental e do Ensino Médio, realizada em um contexto que tem "cem por cento das aulas em laboratório", "cem por cento web", "tudo eletrônico, nada no papel” (P7) (Noções de Ensino de Matemática Usando o Computador). Há também "atividades em que os alunos vão ensinar algum tópico de matemática necessariamente usando alguma mídia, seja Internet, computador, calculadoras, vídeo, revistas e jornais escritos também” (P2) (Ensino de Matemática por Múltiplas Mídias).

Localizamos uma situação que se aproxima do aprender a ensinar com o uso de tecnologias; porém, limitada à discussão, configura-se como "aprender sobre ensinar com o uso de tecnologia" (Metodologia do Ensino de Matemática I e II, ministradas por P4). As situações de uso de tecnologias pelo professor formador na aula são identificadas como "in real time", que consistem em demonstrações do professor aos alunos, em tempo real, durante a aula, com o suporte da tecnologia, e de "uso comum", nome dado por P9 e P10 a exibições em PowerPoint, as quais, aos olhos de P6, possibilitam "dinamizar a aula".

Ainda tratando dos objetivos específicos, buscamos identificar as concepções dos alunos sobre ensino e aprendizagem com TDIC e evidenciar as concepções dos professores formadores e das coordenadoras de curso sobre ensinar com TDIC. Os resultados apontam a concepção otimista entre os alunos, com destaque para o CM1, ao tratarem do potencial da tecnologia para a aprendizagem, e a realista, ao se referirem às possibilidades de implementação no processo de ensino e aprendizagem da escola básica. No tocante ao uso das tecnologias na aula, prevaleceu a tradicional entre os alunos do CM1, e a construcionista entre os do CM2.

Relacionando as concepções dos alunos ao TPACK, em especial as obtidas a partir da aula de Matemática com tecnologias que eles elaboraram - a qual requereu, em certa medida, a aplicação dos conhecimentos aprendidos —, as ocorrências das concepções tradicional e cognitivista sugerem ausência do TPACK, particularmente do TPK, nos quadros referenciais para a docência desses futuros 
professores, com ênfase no CM1, no qual prevaleceu a concepção tradicional, exceto, talvez, pelo domínio do conteúdo matemático, não analisado.

Não pretendemos aqui discutir as relações entre o TPACK e o currículo do curso de formação inicial de professores, tampouco a formação do professor em curso de licenciatura específica; no entanto, cumpre-nos considerar que esses aspectos estão imbricados na discussão sobre a formação do professor. De outro modo, como falar em TPACK em um curso ainda estruturado no modelo da racionalidade técnica?

Ainda sobre as concepções, a realista chama a atenção, por ser comum aos professores e coordenadoras, com exceção de C3, estendendo-se aos alunos. Ao tratar dos usos das tecnologias, entre os professores do CM2 prevalece a concepção construcionista; entre os professores do CM1, a instrucionista. O consenso entre os alunos dos dois cursos e entre esses e alguns professores (P3, P10, P11) sobre as dificuldades para a implementação das TDIC na escola básica dá margem a se questionar porque dificuldades apontadas há mais de 15 anos (PENTEADO, 2000) pela literatura educacional ainda hoje são realidade nas instituições de ensino. Como conseguir a adesão do professor em exercício e do professor em formação em curso de licenciatura para a implementação das TDIC na aula diante desse quadro? Para além dos dispositivos móveis, que hoje podem atenuar a falta de infraestrutura nas instituições de ensino, ainda é preciso equacionar fatores como currículo extenso, falta de tempo, falta de apoio da gestão escolar, falta de valorização das iniciativas dos professores nesse campo etc.

Retomando as concepções dos professores, o que elas informam sobre as suas práticas? Primeiramente, a ocorrência da concepção instrucionista em ambos os cursos, com ênfase no CM1, indica que nas aulas de um e de outro os alunos vivenciaram práticas pedagógicas que tendem a reforçar concepções forjadas no ensino tradicional na escola básica. Num segundo momento, mesmo prevalecendo a concepção construcionista entre os professores do CM2, a oscilação entre essa e a instrucionista nas aulas de um mesmo professor ou de professores distintos do curso pode confundir os alunos quanto ao papel das tecnologias no processo de ensino e aprendizagem.

De modo geral, os dados coletados permitem inferir o que é a formação para o uso das TDIC para os participantes, por meio de indícios como a quantidade de disciplinas apontadas pelos alunos nas quais vivenciaram essa formação; as situações em que essa formação esteve presente, descritas por alunos, professores e coordenadoras; a familiaridade com as tecnologias, a idade do professor e o tempo de experiência profissional apontados por duas coordenadoras (C1 e C3) como fatores que influenciam a adoção ou não de tecnologias nas aulas pelos professores; a premissa de que é somente das disciplinas computacionais a tarefa de preparar o aluno do curso de licenciatura para o uso de tecnologias (P4 e P11), isto é, para o tratamento a ser dispensado às TDIC na escola básica, na dimensão político-pedagógica da sala de aula; a ideia de que conhecimentos sobre tecnologias na educação, por exemplo, o TPACK, devem ser adquiridos em cursos de pós-graduação (P14).

Concluindo, expomos questões latentes, que, à luz dos resultados obtidos, insistem em se pronunciar: se, na prática, a formação para o uso das TDIC, conforme pressuposto neste artigo, não é realidade nos cursos de licenciatura da universidade tida como a número um do País, onde será? Retomando Santos (2009) e sua frustração em face de estudos que mostram que, no Brasil, pouco avançamos na incorporação de tecnologias à educação, qual o caminho para mudar esse quadro e ressignificar a docência, atualmente exercida com alunos da geração digital? Não havendo mudanças, quais os riscos à profissão docente, dada a atual conjuntura da educação pública brasileira? De uma perspectiva gramsciana (GRAMSCI, 1995), enquanto intelectual orgânico, não deveria ser o professor o agente da mudança?

\section{REFERÊNCIAS}

AFONSO, C. A. Internet no Brasil - alguns dos desafios a enfrentar. Informática Pública, v. 4, n. 2, p. 169-184, 2002. 
ALMEIDA, M. E. B. O computador portátil e a inovação educativa: das intenções à realidade. In: ALMEIDA, M. E. B.; DIAS, P.; SILVA, B. D. (Orgs.). Cenários de inovação para a educaşão na sociedade digital. São Paulo: Edições Loyola, 2013. p. 21-33.

ALMEIDA, M. E. B.; VALENTE, J. A. Pesquisa TIC educação: da inclusão para a cultura digital. In: PESQUIS A sobre o uso das tecnologias da informação e comunicação nas escolas brasileiras: TIC educação 2015. São Paulo: Comitê Gestor da Internet no Brasil, 2016. p. 55-67.

BARDIN, L. Análise de conteúdo. 3. reimpr. Lisboa: Edições 70, 2016.

BATISTA, A. R. A formação inicial do professor de matemática: a perspectiva dos formadores das licenciaturas de Presidente Prudente-SP. 2018. 294 f. Dissertação (Mestrado em Educação) - Universidade Estadual Paulista, Faculdade de Ciências e Tecnologia, Presidente Prudente, 2018.

BELLONI, M. L. O que é mídia-educação. 3. ed. Campinas: Autores Associados, 2009.

BRASIL. Ministério da Educação. Resolução CNE/CP 2/2002. Diário Oficial da União, Brasília, 4 de março de 2002, Seção I, p. 9. Institui a duração e a carga horária dos cursos de licenciatura, de graduação plena, de formação de professores da educação básica em nível superior.

CANDAU, V. M. Universidade e formação de professores: que rumos tomar? In: CANDAU, V. M. (Org.). Magistério: construção cotidiana. Petrópolis: Vozes, 1997. p. 30-50.

CETIC. Pesquisa sobre o uso das tecnologias de informação e comunicação nas escolas brasileiras: TIC educação 2017. São Paulo: Comitê Gestor da Internet no Brasil, 2018. Disponível em: https://www.cetic.br/media/docs/publicacoes/2/tic_edu_2017_livro_eletronico.pdf. Acesso em: 02 fev. 2019.

CHAIB, M. Frankstein na sala de aula: as representações sociais docentes sobre informática. Nuances, n. 8, p.47-64, set. 2002.

CIBOTTO, R. A. G.; OLIVEIRA, R. M. M. A. TPACK - Conhecimento Tecnológico e Pedagógico do Conteúdo: uma revisão teórica, Imagens da Educação, v. 7, n. 2, p. 11-23, 2017.

COLL, C.; MAURI, T.; ONRUBIA, J. A incorporação das tecnologias da informação e da comunicação na educação: do projeto técnico-pedagógico às práticas de uso. In: COLL, C.; MONEREO, C. (Orgs.). Psicologia da educação virtual: aprender e ensinar com as tecnologias da informação e da comunicação. Porto Alegre: Artmed, 2010. p. 67-93.

DURAN, M. R. C.; AMIEL, T.; CASTRO, M. História e tecnologia: desafio na formação inicial docente. In: PESQUIS A sobre o uso das tecnologias da informação e comunicação nas escolas brasileiras: TIC educação 2014. São Paulo: Comitê Gestor da Internet no Brasil, 2015. p. 51-58.

FAGUNDES, L. C. Tecnologia e educação: a diferença entre inovar e sofisticar as práticas tradicionais. Revista Fonte, n. 8, p. 6-14, dez. 2008.

FAVA, R. Educaşão 3.0: aplicando o PDCA nas instituições de ensino. São Paulo: Saraiva, 2014.

FREIRE, P. Educação como prática da liberdade. 38. ed. São Paulo: Ed. Paz e Terra, 2014. 
GARNICA, A. V. M. Um ensaio sobre as concepções de professores de Matemática: possibilidades metodológicas e um exercício de pesquisa. Educação e Pesquisa, São Paulo, v. 34, n. 3, p. 495-510, set./dez. 2008.

GATTI, B. A.; BARRETTO, E. S. S.; ANDRÉ, M. E. D. A. Políticas docentes no Brasil: um estado da arte. Brasília: UNESCO, 2011.

GATTI, B. A.; BARRETTO, E. S. S. (Coords.). Professores do Brasil: impasses e desafios. Brasília: UNESCO, 2009.

GRAMSCI, A. Os intelectuais e a organização da cultura. 9. ed. Rio de Janeiro: Civilização Brasileira, 1995.

HORN, M. New research answers whether technology is good or bad for learning. Forbes, published in nov. 14, 2017. Disponível em: https://www.forbes.com/sites/michaelhorn/2017/11/14/newresearch-answers-whether-technology-is-good-or-bad-for-learning/\#567b57d19d7f. Acesso em: 05 fev. 2019.

HOWARD, S. K.; MOZEJKO, A. Teachers: technology, change and resistance. In: HENDERSON, M.; ROMEO, G. (Eds.). Teaching and digital technologies: big issues and critical questions. Port Melbourne, Austrália: Cambridge University Press, 2015. p. 307-317.

KENSKI, V. M. Educação e tecnologias: o novo ritmo da informação. 8. ed. 3. reimpr. Campinas, SP: Papirus, 2014.

MANACORDA, M. A. História da educação: da antiguidade aos nossos dias. 13. ed. São Paulo: Cortez, 2010.

MARCELO GARCIA, C. A formação de professores: centro de atenção e pedra-de-toque. In: NÓVOA, A. (Coord.). Os professores e a sua formação. 3. ed. Lisboa: Dom Quixote, 1997. p. 53-76.

MARCOLLA, V. Como professores e alunos percebem as tecnologias de informação e comunicação nos cursos de licenciatura. In: REUNIÃO ANUAL DA ASSOCIAÇ̃̃O NACIONAL DE PÓSGRADUAÇÃO E PESQUISA EM EDUCAÇÃO, 31, 2008, Caxambu. Anais... Caxambu: ANPEd, 2008. p. 1-13.

MARCO, F. F. Atividades computacionais de ensino na formação inicial do professor de matemática. Tese (Doutorado em Educação) - Universidade Estadual de Campinas, Faculdade de Educação, Campinas, SP, 2009.

MASETTO, M. T. Docência universitária: repensando a aula. In: TEODORO, A.; VASCONCELOS, M. L. M. C. (Orgs.). Ensinar e aprender no ensino superior: por uma epistemologia da curiosidade na formação universitária. 3. ed. São Paulo: Universidade Presbiteriana Mackenzie; Cortez, 2012. p. 79106.

MIZUKAMI, M. G. N. Docência, trajetórias pessoais e desenvolvimento profissional. In: REALI, A. M. M. R.; MIZUKAMI, M. G. N. (Orgs.). Formação de professores: tendências atuais. São Carlos: EDUFSCar, 1996. p. 59-91.

MIZUKAMI, M. G. N. Ensino: as abordagens do processo. São Paulo: EPU, 1986.

MIZUKAMI, M. G. N. et al. Escola e aprendizagem da docência: processos de investigação e formação. São Carlos: EdUFSCar, 2002. 
MOREIRA, M. A. Teorias de aprendiragem. 2. ed. São Paulo: EPU, 2011.

PALFREY, J. Nascidos na era digital: entendendo a primeira geração de nativos digitais. Porto Alegre: Artmed, 2011.

PAPERT, S. The children's machine: rethinking school in the age of the computer. New York: BasicBooks, 1992.

PENTEADO, M. Possibilidades para a formação de professores de Matemática. In: PENTEADO, M; BORBA, M. C. (Orgs.). A informática em ação: formação de professores, pesquisa e extensão. São Paulo: Olho d'Água, 2000. p. 23-34.

PENTEADO, M. G.; SKOVSMOSE, O. Riscos trazem possibilidades. In: SKOVSMOSE, O. (Org.). Desafios da reflexão em Educação Matemática Crítica. Campinas: Papirus, 2008. p. 41-50.

PÉREZ GÓMEZ, A. O pensamento prático do professor: a formação do professor como profissional reflexivo. In: NÓVOA, A. (Org.). Os professores e a sua formação. 3. ed. Lisboa: Dom Quixote, 1997. p. 95-114.

PIRES, C. M. C. Reflexões sobre os cursos de Licenciatura em Matemática, tomando como referência as orientações propostas nas Diretrizes Curriculares Nacionais para a formação de professores da Educação Básica. Revista da Sociedade Brasileira de Educação Matemática. São Paulo, n. 11, p. 44-56, abr. 2002.

PONTE, J. P. Tecnologias de informação e comunicação na formação de professores: que desafios? Revista Iberoamericana de Educación, n. 24, p. 63-90, 2000.

ROSADO, E. M. S. Contribuições da psicologia para uso da mídia no ensino-aprendizagem. In: ENCONTRO NACIONAL DE DIDÁTICAS E PRÁTICA DE ENSINO, 9, 1998, Águas de Lindóia. Anais... Águas de Lindóia: [s.n.], 1998. p. 217-237.

SANTAELLA, L. Cultura das mídias. 3. ed. rev. ampl. São Paulo: Experimento, 2003.

SANTOS, E. T. A formação dos professores para o uso das tecnologias digitais nos GTs Formação de Professores e Educação e Comunicação da ANPEd - 2000 a 2008. In: REUNIÃO NACIONAL DA ANPED, 32, 2009, Caxambu. Anais... Caxambu: ANPEd, 2009. p. 1-15.

SANTOS, F. A. Da perspectiva analógica ao contexto digital: desafios à inserção das tecnologias digitais na EJA. REUNIÃO NACIONAL DA ANPED, 38, 2017, São Luiz. Anais... São Luiz, Maranhão: ANPEd, 2017. p. 1-17.

SANTOS, G. H.; ALVES, L. ; MORET, M. A. Modellus: animações interativas mediando a aprendizagem significativa dos conceitos de física no ensino médio. Revista científica da escola de administração do exército, v. 2, p. 88-108, 2006.

SANTOS, G. L. Formar professores para a educação mediada por tecnologias: elucidação da problemática por meio de seis investigações acadêmicas. In: SANTOS, G. L.; ANDRADE, J. B. F. (Orgs.). Virtualizando a escola: migrações docentes rumo à sala de aula virtual. Brasília: Ed. Líber Livro, 2010. p. 15-28. 
SANTOS, L. L. C. P. Formação de Professores e saberes docentes. In: NETO, A. S.; MACIEL, L. S. B. (Orgs.). Reflexões sobre a formação de professores. São Paulo: Papirus, 2002. p. 89-101.

SÃO PAULO. Pró-Reitoria de Graduação. Programa de Formação de Professores. São Paulo: [s.n.], 2004.

SCHÖN, D. A. Formar professores como profissionais reflexivos. In: NÓVOA, A. (Coord.). Os professores e a sua formação. Lisboa: Dom Quixote, 1997. p. 77-91.

SOUSA, S. O. Aprendizagem Baseada em Problemas (PBL - Problem-Based Learning) estratégia para ensino e aprendizagem de algoritmos e conteúdos computacionais. Dissertação (Mestrado em Educação) Universidade Estadual Paulista, Faculdade de Ciências e Tecnologia, Presidente Prudente, SP, 2010.

TARDIF, M. Saberes docentes e formação profissional. Petrópolis: Vozes, 2002.

VALENTE, J. A. Análise dos diferentes tipos de software usados na educação. In: VALENTE, J. A. (Org.). O computador na sociedade do conhecimento. Campinas: UNICAMP, 1999. p. 89-110.

VALENTE, J. A. Diferentes usos do computador na educação. In: VALENTE, J. A. (Org.). Computadores e conhecimento: repensando a educação. Campinas: UNICAMP, 1993. p. 1-23. 